\title{
É possível economizar energia nas estações de tratamento de esgoto?
}

Is it possible to save energy in sewage treatment plants?

\section{INTRODUÇÃO E OBJETIVO}

As referências internacionais para a parcela relacionada aos custos de energia nas Estações de Tratamento de Esgoto (ETEs) indicam que ela pode se situar entre $25 \%$ e $50 \%$ dos custos operacionais (WEF, 2002). No Brasil, esse percentual é reduzido pela influência maior que tem a parcela de pessoal nos custos de operação da ETE, como mostra a Figura 1, referente à ETE Barueri (SP), com vazão média de $12 \mathrm{~m}^{3} / \mathrm{s}$ (JORDÃO; PESSÔA, 2014); no caso específico, os custos com pessoal representam $48 \%$ do total, reduzindo, assim, o peso do quesito energia elétrica para $20 \%$. Considerando, no entanto, que há a tendência de melhorar os processos de controle e automação e reduzir o número de operadores nas ETEs, é razoável admitir como significativo entre nós o peso da energia nos seus custos operacionais.

\section{CONSUMO DE ENERGIA}

É razoável admitir também que o consumo de energia varia com o processo adotado. $O$ processo de lodos ativados é, de longe, o que apresenta maior consumo, sendo sua variável de "aeração estendida" a que mais requer energia.

Sabe-se que $30 \%$ a $80 \%$ (ou $50 \%$, como indicador médio) do consumo de energia elétrica na ETE se concentra na fase biológica do processo de lodos ativados. A Figura 2 relaciona o consumo

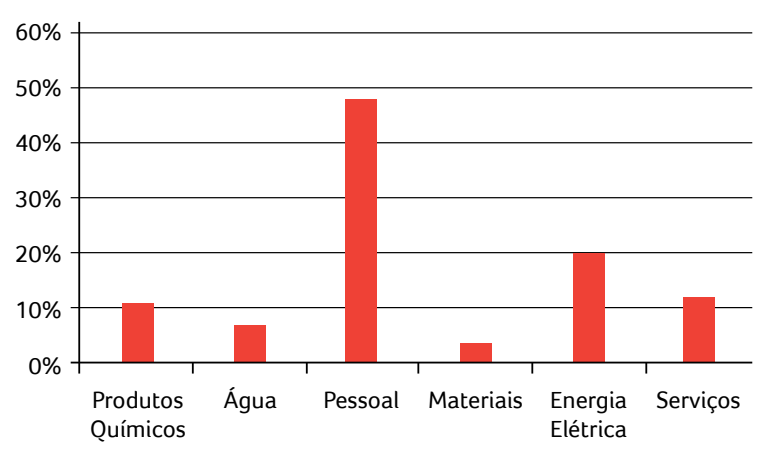

Figura 1 - Custos operacionais (\%) na ETE Barueri (anteriores a 2015).

típico (mínimo) de energia elétrica requerida nos processos de filtração biológica, lodos ativados convencional e lodos ativados com nitrificação e filtração (dados para ETEs até $5 \mathrm{~m}^{3} / \mathrm{s}$ ) (WEF, 2002). Observa-se um percentual típico de consumo de energia entre $20 \%$ e $50 \%$ nos casos de remoção apenas da Demanda Bioquímica de Oxigênio (DBO) carbonácea; já nos casos em que ocorre nitrificação, de $30 \%$ a quase $60 \%$.

Dados típicos de estações norte-americanas mostram as seguintes faixas de consumo de energia para os processos (WEF, 2002):

- lodos ativados por aeração prolongada e valos: 1.500 a $1.900 \mathrm{~kJ} / \mathrm{m}^{3}$;

- lodos ativados no processo convencional: 1.200 a $1.700 \mathrm{~kJ} / \mathrm{m}^{3}$; 


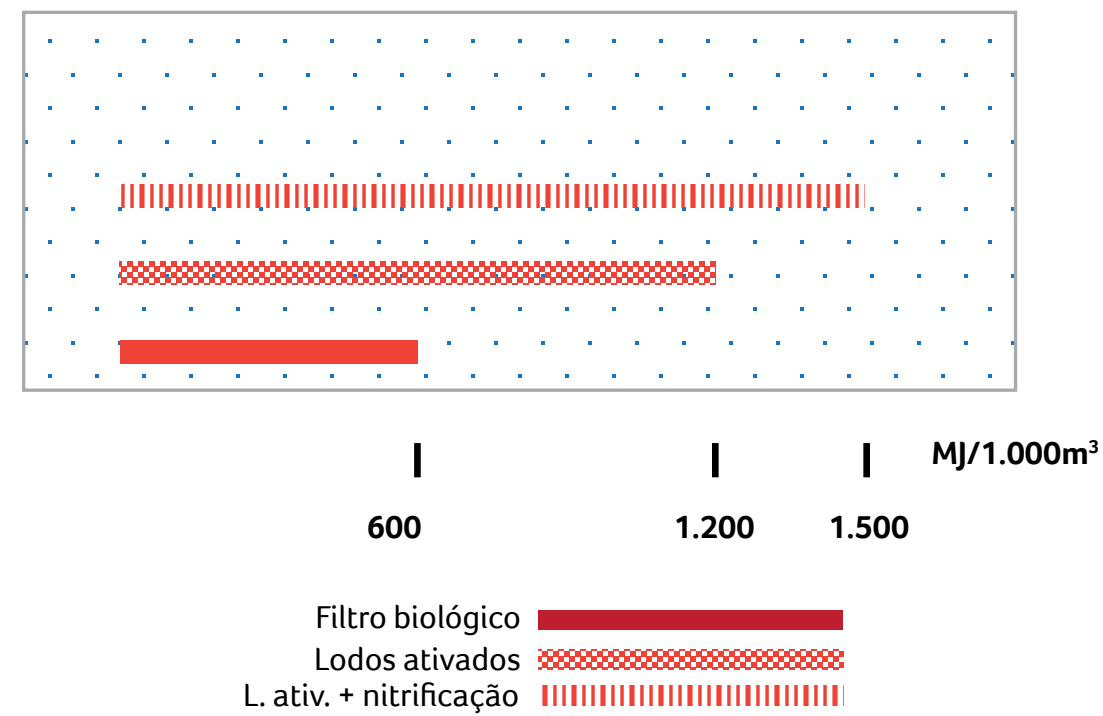

Figura 2 - Energia elétrica MJ/1.000 m³ x processos.

- filtros biológicos e processos com massa aderida: 700 a $1.200 \mathrm{~kJ} / \mathrm{m}^{3}$;

- como referência, $1 \mathrm{kWh}=3.600 \mathrm{~kJ} ; 1 \mathrm{~kJ} / \mathrm{m}^{3}=1$ $\mathrm{MJ} / 1.000 \mathrm{~m}^{3} ; 1 \mathrm{MJ}=10^{3} \mathrm{~kJ}$.

A Tabela 1 mostra alguns indicadores que podem ser usados para verificar o comportamento energético da ETE (WEF, 2002).

Tabela 1 - Consumo médio de energia em ETEs (típico).

\begin{tabular}{|c|c|}
\hline \multicolumn{1}{|c|}{ Função } & \multicolumn{1}{c|}{ Consumo } \\
\hline Vazão afluente & $1.500 \mathrm{~kJ} / \mathrm{m}^{3}$ \\
\hline SST afluente & $12.550 \mathrm{~kJ} / \mathrm{kg} \mathrm{SST}$ \\
\hline DBO afluente & $13.000 \mathrm{~kJ} / \mathrm{kg} \mathrm{DBO}$ \\
\hline Fornecimento de ar & $330 \mathrm{~kJ} / \mathrm{m}^{3}$ \\
\hline Produção de lodo & $793.650 \mathrm{~kJ} / \mathrm{m}^{3}$ \\
\hline Produção de lodo & $26.520 \mathrm{~kJ} / \mathrm{kg}$ \\
\hline \multicolumn{2}{|c|}{ Fonte: WEF (2002). } \\
\hline \multicolumn{2}{|c|}{ Nota: SST = sólidos suspensos totais. } \\
\hline \multicolumn{2}{|c|}{}
\end{tabular}

\section{CRITÉRIOS INICIAIS}

O primeiro critério visando à redução do consumo de energia em uma ETE é a escolha do processo, evidentemente. Processos de aeração estendida não devem absolutamente ser escolhidos em casos de estações de tratamento de médio e grande porte, sendo, na verdade, indicados praticamente apenas para estações condominiais ou de pequenas indústrias.

Se a eficiência da ETE puder ser da ordem de $85 \%$ (e não 95\%, como quase sempre se especifica) e se houver área disponível, um processo de filtros biológicos será bem adequado e muito econômico. Aliás, não há razão para considerá-lo antiquado e ultrapassado, apenas porque sua eficiência é cerca de $10 \%$ a $15 \%$ menor que os modernos processos de lodos ativados - modernos, apesar de já terem completado 100 anos de vida!

O segundo critério que se pode adotar para reduzir o consumo de energia nas ETEs é disponibilizar um sistema de medição e controle de dados que permita o acompanhamento da operação em tempo real. 0 consumo de energia nas diferentes unidades da estação deve ser conhecido e pode ser relacionado aos indicadores clássicos, para verificação do comportamento da ETE, como apresentado na Tabela 1, já mencionada. 
O terceiro ponto que pode ser considerado é a própria implantação das etapas da estação. Normalmente, a ETE é projetada e implantada em etapas, sendo usual adotar pelo menos duas, de modo que os investimentos possam ser escalonados e a acompanhar o crescimento da vazão e extensão da rede. Entretanto, nem sempre a implantação segue esse critério, sendo comum ter uma estação inaugurada e fortemente superdimensionada. Nesse caso, se todos os aeradores estiverem operando - o que é muito comum e até necessário para manter os sólidos em suspensão no meio -, estarão disponibilizando ar ou oxigênio em excesso, de forma desnecessária, e a energia consumida também será excessiva.

\section{PROCESSO BIOLÓGICO}

O processo de lodos ativados é sem dúvida, entre os processos biológicos, o mais usado e eficiente em tratamento de esgoto, com eficiência de remoção da DBO superior a $90 \%$, ou mesmo $95 \%$. Cabem, portanto, alguns comentários em relação ao projeto nesse processo, visando a reduzir o consumo de energia, que pode muitas vezes ser excessivo.

A primeira observação diz respeito ao número de unidades ou tanques de aeração, que deve ser escolhido de forma a poder acompanhar o crescimento da expansão da rede coletora ou vazão afluente. Em outras palavras, o projeto deve conceber um número de etapas cuja implantação seja factível com o esperado crescimento da própria estação.

A modalidade do processo de lodos ativados irá também influir no consumo de energia. Processos de lodos ativados por aeração prolongada se caracterizam por ter uma relação alimento/microrganismo ( $A / M)$ muito baixa, o que induz a elevados tempos de detenção e grandes volumes de reator. Esses "grandes volumes", evidentemente, requerem maior energia para que se mantenham os sólidos em suspensão no tanque de aeração, pois os aeradores devem garantir, igualmente, uma agitação elevada para disponibilizar o oxigê- nio necessário ao meio aquático, mas igualmente para manter os sólidos em suspensão nos reatores. Muitas vezes, a potência para mistura governa o dimensionamento, "sobrando" oxigênio para satisfazer os microrganismos. Tipicamente, a relação necessária para agitação, no caso de aeradores superficiais mecânicos, é da ordem de 30 W/ $\mathrm{m}^{3}$, variando de 20 a $40 \mathrm{~W} / \mathrm{m}^{3}$, sendo interessante, assim, trabalhar, se possível, com unidades de aeração com menor tamanho.

No caso de sistemas empregando compressores de ar, com os difusores montados em todo o fundo do tanque de aeração, pode-se recomendar cerca de 10 a $15 \mathrm{~m}^{3} \mathrm{ar} / \mathrm{min}$ por $1.000 \mathrm{~m}^{3}$ de volume do tanque. Assim, pretende-se reduzir os volumes de aeração e, eventualmente, aumentar a relação $\mathrm{A} / \mathrm{M}$, de acordo com as disponibilidades. A Tabela 2 mostra indicações relacionando a potência do aerador superficial a dimensões apropriadas do tanque de aeração.

Outro ponto interessante a verificar é se os cálculos efetuados são condizentes com os indicadores típicos do processo de lodos ativados, como, por exemplo, a energia usualmente consumida no processo, por volume de esgoto tratado. Esse número tem variado de 250 a $400 \mathrm{kWh} / 1000 \mathrm{~m}^{3}$ de esgoto tratado no processo de lodos ativados, de acordo com o porte da ETE e o programa de "gestão de energia" ou "eficiência energética" implantado na estação (JORDÃO, 2009). Indicadores semelhantes foram apresentados na Tabela 1.

Tabela 2 - Dimensões sugeridas para os tanques de aeração.*

\begin{tabular}{|c|c|c|c|}
\hline \multicolumn{2}{|c|}{ Potência } & Lado & Profundidade \\
\hline HP & kW & $m$ & m \\
\hline 10 & 7,5 & $9-12$ & $3-3,5$ \\
\hline 20 & 15 & $10-15$ & $3,5-4$ \\
\hline 40 & 30 & $14-20$ & $3,5-5$ \\
\hline 75 & 55 & $14-26$ & $4,5-6$ \\
\hline 100 & 75 & $18-27$ & $4,5-6$ \\
\hline
\end{tabular}

Fonte: Jordão e Pessôa (2014). Nota: * Área de influência do rotor de aeração. 


\section{GERAÇÃO DE LODO E GÁS}

O lodo é o mal necessário de toda ETE. Seu tratamento implica elevados custos de construção de adensadores, digestores e sistemas de secagem, como também elevados custos de operação, além do transporte e bota-fora do produto final de seu tratamento, o lodo seco.

Se o objetivo é remover o máximo possível de DBO e sólidos, na fase líquida da ETE, mesmo antes da implantação do tratamento secundário, é possível, com auxílio de reagentes químicos, conseguir uma substancial precipitação química da matéria sólida. São processos chamados "avançados" (tratamento primário avançado ou quimicamente assistido), em que se ganha de um lado (na fase líquida) e se perde do outro (na fase sólida), sendo típico um acréscimo na remoção de sólidos - e na produção de lodo - da ordem de 30\% a 35\%. Goiânia e Rio de Janeiro são duas cidades que implantaram processos quimicamente assistidos com razoável vazão, evidentemente, a um custo operacional elevado.

Em geral, esses processos chamados "primários avançados” são aplicados de forma transitória, até que os investimentos para implantação do tratamento secundário na estação, na sua forma clássica e final, estejam disponíveis. Cabe, no planejamento da nova ETE, pesar as vantagens ao implantar tais processos, bem como os custos operacionais advindos. Na verdade, a melhor indicação é realizar um estudo de custos ao longo da vida útil do projeto e trazer os resultados a valor presente para uma justa avaliação.

Atualmente, o que não deve ser subestimado é a geração de gás nos digestores. A experiência alemã é talvez a mais pródiga em apresentar estações de tratamento com recuperação do gás gerado e seu aproveitamento como energia elétrica e térmica. Os alemães não estão somente preocupados em tratar os sólidos dos esgotos e gerar gás em digestores de lodo; eles já estão produzindo energia a partir do gás gerado em fermentadores de lodo de esgoto, de esterco bovino, de bagaço de malte, de resíduos de hortaliças, cereais e refugo de batatas, por exemplo. O principal subproduto originado na produção da cerveja (e os alemães são "craques" nisso) é o bagaço do malte, que responde por $75 \%$ do total. Por hectolitro de cerveja, são produzidos cerca de $19 \mathrm{~kg}$ de bagaço de cevada, que, com outros subprodutos, são encaminhados a usinas de biogás (FNR, 2010).

Veja-se: não se está mais falando em digestor que produz gás, mas em usina de biogás, que usa um processo de digestão anaeróbia. Em outras palavras, os processos são os mesmos, mas os objetivos são, agora, gerar gás e produzir energia. 0 mesmo vale para a produção de biodiesel, em que os subprodutos são usados como substratos em usinas de biogás agrícolas, que apresentam elevado rendimento de biogás. Ademais, o biogás gerado, quer nos digestores de lodo de esgotos, quer nas usinas de gás alemãs, tem composição muito semelhante: $65 \%$ a $75 \%$ de metano, $25 \%$ a $30 \%$ de gás carbônico, $2 \%$ a $4 \%$ de óxido de carbono e quantidades menores de outros componentes (oxigênio, nitrogênio, hidrocarbonetos e gás sulfídrico).

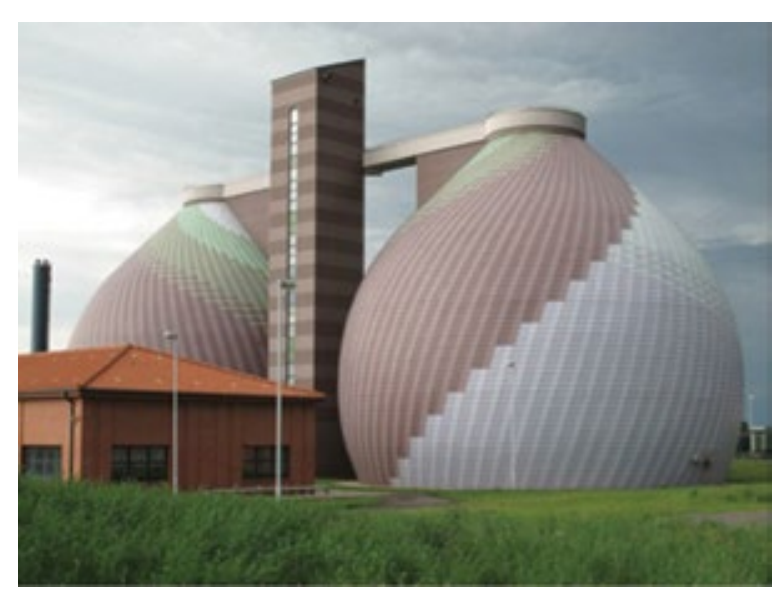

Figura 3 - Moderno digestor anaeróbio da ETE Magdeburg, Alemanha.

Foto: Victor Valente. 
A Alemanha possuía, no ano 2000 , cerca de mil usinas de biogás; em dez anos, esse número aumentou para mais de cinco mil, com potência de energia elétrica gerada de $70 \mathrm{~kW}$ até mais de 1 MW, embora a maioria esteja na faixa de 70 a 500 kW. Este é um exemplo novo a considerar, vendo os digestores sob a óptica das usinas de biogás alemãs. A Figura 3 mostra o moderno digestor (ou usina de biogás) da ETE Magdeburg, na Alemanha.

\section{ÍNDICES DE EFICIÊNCIA}

É sabido que o gás gerado na digestão anaeróbia de lodo de esgotos é da ordem de 15 a 20 L/ hab.d para lodo primário e 25 a 30 L/hab.d para lodo misto. Referido à outra base, o gás produzido no digestor recebendo lodo misto apresenta volume de cerca de 0,8 a $1,1 \mathrm{~m}^{3} / \mathrm{kg}$ de sólidos voláteis destruídos, variando principalmente com a temperatura em que se processa a digestão (JORDÃO; PESSÔA, 2014).

É interessante acompanhar o estudo realizado pelos autores para uma ETE em Uberaba (MG) - ETE clássica de lodos ativados, porém não implantada (JORDÃO; PESSÔA, 2014):

- vazão de projeto: $55.000 \mathrm{~m}^{3} / \mathrm{d}$;

- população contribuinte: 220.000 hab;

- DBO unitária: 54 g DBO/hab.d;

- eficiência de remoção da DBO na ETE: 90\%;

- DBO removida para eficiência de $90 \%: 10.692$ $\mathrm{kg} \mathrm{DBO/d;}$

- sólidos totais afluentes ao digestor: $10.227 \mathrm{~kg}$ $\mathrm{ST} / \mathrm{d}$;

- sólidos voláteis afluentes ao digestor: $7.670 \mathrm{~kg}$ $\mathrm{SV} / \mathrm{d}$;

- sólidos voláteis destruídos na digestão - admitido 60\%: 4.602 kg SV/d;
- volume de gás gerado (para 0,8 a $1,1 \mathrm{~m}^{3} / \mathrm{kg}$ de SV destruído): 3.681 a $5.062 \mathrm{~m}^{3}$ gás/d;

- poder calorífico do biogás: $22.400 \mathrm{~kJ} / \mathrm{m}^{3}$;

- energia bruta produzida: $22.400 \mathrm{~kJ} / \mathrm{m}^{3} \times(3.681$ a $\left.5.062 \mathrm{~m}^{3} \mathrm{gás} / \mathrm{d}\right)=22.905$ a $31.500 \mathrm{kWh} / \mathrm{d}$ (sendo $27.202 \mathrm{kWh} / \mathrm{d}$ o valor médio);

- aproveitamento bruto de energia por DBO removida: [(22.905 a $31.500 \mathrm{kWh} / \mathrm{d}) /(10.692 \mathrm{~kg}$ $\mathrm{DBO} / \mathrm{d})]=2,1$ a $2,9 \mathrm{kWh} / \mathrm{kg}$ DBO removida;

- eficiência de aproveitamento como energia elétrica: 25\% (a eficiência é comprovadamente baixa, de acordo com a Tabela 3);

- aproveitamento como energia elétrica: [0,25 $x(22.905$ a $31.500 \mathrm{kWh} / \mathrm{d})]=5.726$ a 7.875 $\mathrm{kWh} / \mathrm{d}=[(5.726$ a $7.875 \mathrm{kWh} / \mathrm{d} \times 365 \mathrm{~d} / \mathrm{ano}) /$ (220.000 hab)] = 9,5 a 13,0 kWh/hab.ano.

Tabela 3 - Eficiência de aproveitamento em energia elétrica.

\begin{tabular}{|c|c|c|}
\hline Tecnologia & $\begin{array}{c}\text { Faixa de potência } \\
\mathbf{( k W )}\end{array}$ & $\begin{array}{c}\text { Eficiência } \\
\text { elétrica (\%) }\end{array}$ \\
\hline Motor a combustão & $100-4.000$ & $30-42$ \\
\hline Turbina a gás & $1.000-4.600$ & $25-38$ \\
\hline Microturbina & $70-250$ & $24-26$ \\
\hline Célula combustível & $200-300$ & $38-42$ \\
\hline
\end{tabular}

Fonte: Jordão e Pessôa (2014).

A experiência alemã indica um aproveitamento de 10 a $15 \mathrm{kWh} / \mathrm{hab}$.ano para geração de energia elétrica (JORDÃO; PESSÔA, 2014), praticamente o mesmo encontrado nos cálculos realizados para a ETE Uberaba (9,5 a 13,0 kWh/hab.ano).

Em Santiago, no Chile, as ETEs La Farfana e El Trebal (de grande porte, respectivamente com 9 e 4 $\mathrm{m}^{3} / \mathrm{s}$ ) praticam a cogeração de energia a partir do gás de seus digestores, tendo a última apresentado em 2013 um aproveitamento de cerca de $1,3 \mathrm{kWh} / \mathrm{kg}$ DBO removida. Esse valor é cerca de metade do que mostra a experiência alemã, mas, 
à época, seus digestores sofriam uma instabilidade no processo, o que poderia ter sido provocado pelo terremoto que atingiu o Chile em 2011. Não obstante, indica-se que a cogeração de energia já atende a cerca de $60 \%$ a $70 \%$ das necessidades da estação de tratamento, o que representa um número muito elevado (TRUMPER; LESTY, 2015).

Ainda no exemplo da ETE Uberaba, o potencial de eletricidade disponibilizada (que é o rendimento global da transformação em energia elétrica), calculado como cerca de $25 \%$ da energia bruta produzida, seria em condições extremas:

- $[(0,25 \times 22.905 \mathrm{kWh} / \mathrm{d}) /(24 \mathrm{~h} / \mathrm{d})]=239 \mathrm{~kW}$;

- $[(0,25 \times 31.500 \mathrm{kWh} / \mathrm{d}) /(24 \mathrm{~h} / \mathrm{d})]=328 \mathrm{~kW}$.

Esses números são condizentes com a referência alemã, de aproveitamento de 10 a 15 kWh/hab. ano para geração de energia elétrica a partir do biogás do digestor, que seria, então, cerca de (eletricidade disponibilizada):

- $[(10 \mathrm{kWh} / \mathrm{hab} . a n o x 220.000 \mathrm{hab}) /(365 \mathrm{~d} / \mathrm{anox}$ $24 \mathrm{~h} / \mathrm{d})]=251 \mathrm{~kW}$;

- $[(15 \mathrm{kWh} / \mathrm{hab} . a n o x 220.000 \mathrm{hab}) /(365 \mathrm{~d} / \mathrm{ano} \mathrm{x}$ $24 \mathrm{~h} / \mathrm{d})]=377 \mathrm{~kW}$.

Admitindo que uma ETE de lodos ativados clássica possa consumir cerca de 330 a $470 \mathrm{kWh} / 1.000$ $\mathrm{m}^{3}$ (WEF, 2002), o consumo para a ETE Uberaba, em estudo, chegaria a cerca de: [(330 a 470 $\left.\left.\mathrm{kWh} / 1.000 \mathrm{~m}^{3}\right) \times\left(55.000 \mathrm{~m}^{3} / \mathrm{d}\right)\right]=18.150$ a 25.850 $\mathrm{kWh} / \mathrm{d}=756$ a $1.077 \mathrm{~kW}$.

Ora, a energia elétrica disponibilizada, segundo os cálculos apresentados, pode representar, na meIhor hipótese, até cerca de $50 \%$ das necessidades de consumo na estação, um ótimo aproveitamento nesse caso. Resta verificar os custos do próprio aproveitamento e a capacidade operacional para atingir os melhores índices de eficiência.

\section{INDICAÇÕES}

Algumas indicações podem ser feitas para usufruir desse benefício e garantir um bom programa de conservação de energia na estação de tratamento. Elas vão desde a realização de uma operação criteriosa até o acompanhamento dos serviços de manutenção preventiva e corretiva dos equipamentos, podendo incluir a conservação e o aproveitamento de energia na ETE:

- estabelecer um programa de conservação de energia na ETE;

- verificar qual seria a menor concentração de oxigênio dissolvido para manter no tanque de aeração, satisfazendo a eficiência desejada de tratamento;

- para o set-point indicado, manter sistemas de controle que contínua e automaticamente ajustem o fornecimento de ar à demanda de oxigênio, atuando sobre os compressores e reduzindo o consumo;

- os sopradores devem ser escolhidos para operar próximo do ponto de melhor eficiência;

- no tanque de aeração, utilizar difusores somente de bolha fina;

- idealmente, as bombas também devem trabalhar próximo do ponto de melhor eficiência. Inversores de frequência podem melhorar sua eficiência;

- tubulações de recalque mal projetadas ou com quantidade excessiva de peças especiais podem significar aumento indesejado de perdas de carga e energia;

- motores que operam continuamente devem ser criteriosamente especificados, visando à minimização da energia. A manutenção preventiva dos componentes mecânicos e elétricos não deve ser negligenciada;

- embora a energia seja relativamente barata no Brasil, no caso do saneamento, verificar as 
vantagens de usar o gás dos digestores como fonte de energia;

- o gás dos digestores pode eventualmente ser usado como combustível no sistema de secagem do lodo;

- manter um sistema de controle com o histórico dos principais equipamentos da ETE;

- estabelecer um acompanhamento dos custos principais da ETE, tais como: pessoal, energia elétrica, manutenção preventiva e corretiva, produtos químicos, gestão do lodo;

- com foco nos custos da ETE, comparar a estação com outras semelhantes e tentar estabelecer um processo de benchmarking: como se posicionam seus custos por metro cúbico de esgoto tratado ou por remoção de DBO, por exemplo? O que recomendam as publicações especializadas?

- discutir periodicamente os resultados do programa de conservação de energia com os operadores.

\section{REFERÊNCIAS}

Barjenbruch, M. - Anais do Seminário de Sustentabilidade de Estações de Tratamento, ABES-Rio, 2011

Fechagentur Nachwachsende Rohstoffe (FNR) e. V. - Guia Prático do Biogás, Probiogás (Ministério das Cidades e GIZ), tradução do original alemão LeitfadenBiogas, $5^{\text {a }}$ edição, 2010

Jordão, E.P., Eficiência Energética em Tratamento de Esgotos, Revista DAE, 2009

Jordão, E.P., Pessôa, C.A. - Tratamento de Esgotos Domésticos, ABES, $7^{a}$ edição, 2014

Trumper B.A; Lesty, Y. - 14 Years of the First Large WWTP in Chile, IWA LWWTP Conference, Praga, 2015

USEPA - Ensuring a sustainable future: an energy management guidebook for wastewater and water utilities, Environmental Protection Agency, 2008

WEF, Activated Sludge, Manual of Practice no. 9, Water Environment Federation, 2002 